\title{
Body weight as a determinant of saccharin consumption in the orchidectomized male hamster (Mesocricetus auratus)
}

\author{
H. E. MARKS* \\ Wofford College, Spartanburg, S.C. 29301
}

The saccharin intake of intact and orchidectomized male hamsters were compared at points at which (1) no weight differences existed between the groups, (2) the intact group had outgained the orchidectomized group, and (3) the orchidectomized group had outgained the intact group. Where no weight differences existed, no intake differences were observed. Where one group had gained more weight than the other, it drank less saccharin, regardless of its surgical condition. It was suggested that body weight might be a critical variable in the control of saccharin consumption in neutered male hamsters.

The one study in the literature investigating the effects of gonadectomy on taste preference in hamsters (Zucker, Wade, \& Zeigler, 1972) suggests that, since some changes in saccharin preference occur following gonadectomy in hamsters, the results of hamster research supports the general conclusions found using rats as experimental Ss (Wade \& Zucker, 1969, 1970; Zucker, 1969). These conclusions suggest that alternations in saccharin preference following gonadectomy is a direct function of changes in the level of gonadal hormones rather than a function of gonadectomy-induced weight changes.

Since a previous study with hamsters demonstrated the necessity for a preferred food in order to demonstrate the weight gain associated with hypothalamic hyperphagia (Marks \& Miller, 1972), it was felt that an appropriate test of the effects of gonadectomy in hamsters would have to take this potential food preference variable into account.

\section{EXPERIMENT I Method}

Fourteen male Syrian Golden Hamsters (Mesocricetus auratus), approximately 70 days old at the time of surgery, were used. All hamsters were housed in individual cages with free access to water, except during testing periods. A preferred food, wheat germ, was continuously available. Wheat germ was chosen since preliminary studies had indicated consistent preferences for wheat germ compared to Lab Chow. A 12:12 light:dark cycle was maintained throughout the experiment. Eight males were orchidectomized under sodium pentobarbital (Nembutal, $90 \mathrm{mg} / \mathrm{kg}$ ) anesthesia. Control-group hamsters were sham-operated. Food intake and body weight were recorded daily.

One week prior to surgery, water intake was measured for $4 \mathrm{~h}$ per day for 5 consecutive days in each hamster's home cage.

*The author would like to express his appreciation to $R$. Montemayor for his able assistance in collecting the data. A portion of these data were presented at the 1973 meeting of the Southern Society for Philosophy and Psychology. Reprint requests should be sent to $H$. E. Marks, Department of Psychology, University of South Carolina, Lancaster, S.C. 29720.
Three days following surgery, and prior to the development of between-group weight differences, all animals received a $0.1 \%$ saccharin solution for $4 \mathrm{~h}$ per day during a 5-day testing period. A second saccharin test was begun 100 days postoperatively, following the development of reliable between-group weight differences, using the same procedures as the first saccharin test. A 10-day ( $4 \mathrm{~h}$ per day) water intake measure was taken 20 days after the conclusion of the second saccharin tes ${ }^{\dagger}$. In all tests, consumption was measured to the nearest $0.1 \mathrm{ml}$.

\section{Results}

No statistically significant differences in preoperative body weights were found between the two groups $(\mathrm{t}=$ $1.24, \mathrm{df}=12, \mathrm{p}>.05) .{ }^{1}$ Water intake measures revealed no reliable differences between the groups, either pre- $(\mathrm{F}$ $=1.68, \mathrm{df}=1 / 12, \mathrm{p}>.05)$ or postoperatively $(\mathrm{F}=1.09$, $\mathrm{df}=1.12, \mathrm{p}>.05)$.

During the initial consumption test, the orchidectomized hamsters lost slightly, but statistically nonsignificantly, more weight than the intact hamsters $(\mathrm{F}<1.0)$. During this first test, the intact hamsters consumed slightly less saccharin than the orchidectomized hamsters, but, again, the difference was not statistically significant $(\mathrm{F}<1.0$; Table 1$)$.

Both groups of animals regained their preoperative body weights and continued to gain weight above preoperative levels. By 100 days following surgery, a reliable weight difference had been established, with the intact group having gained more weight than the orchidectomized group $(F=5.01, \mathrm{df}=1 / 12, \mathrm{p}<.05)$. During this second test, the orchidectomized hamsters consumed reliably more saccharin than the intact animals $(F=4.89, \mathrm{df}=1 / 12, \mathrm{p}<.05)$.

No reliable differences between the groups in terms of food intake was found at any point during the experiment. While both groups showed comparatively low intakes (intact $=3.9 \mathrm{~g} / \mathrm{day}$, orchidectomized $=$ $3.7 \mathrm{~g} /$ day), food intake differences were directly correlated with weight gain differences. The reduced intake was probably a function of the comparatively high caloric value of wheat germ (Robinson, 1967).

Since a relationship between body weight change following orchidectomy and saccharin consumption had been demonstrated in the first experiment, but no reliable differences in food intake were found using wheat germ, an attempt was made to determine the effects of Lab Chow on body weight and saccharin preference in orchidectomized hamsters.

\section{EXPERIMENT II \\ Method}

Twelve of the original 14 hamsters were used in this second experiment; 2 orchidectomized hamsters were excluded due to illness. Maintenance conditions were identical with those of the first experiment, except that powdered Purina Lab Chow was 
Table 1

Mean Weight Gain and Saccharin Intake for Two Tests: Experiment I

\begin{tabular}{lccccc}
\hline & \multicolumn{2}{c}{ First } & Test & & \multicolumn{2}{c}{ Second Test } \\
\cline { 2 - 3 } \cline { 5 - 6 } & $\begin{array}{c}\text { Body } \\
\text { Weight* }\end{array}$ & $\begin{array}{c}\text { Saccharin } \\
\text { Intaket }\end{array}$ & & $\begin{array}{c}\text { Body } \\
\text { Weight }\end{array}$ & $\begin{array}{c}\text { Saccharin } \\
\text { Intake }\end{array}$ \\
\hline Intact & -2.8 & 4.0 & & +24.5 & 3.4 \\
Orchidectomized & -6.1 & 4.2 & & +15.2 & 4.9 \\
p & n.s. & n.s. & & .05 & .05 \\
\hline
\end{tabular}

${ }^{*}$ Body weight was computed as the change. in grams, from preoperative body weight.

$\div$ Mean intake in milliliters over the 5-day testing period.

used instead of wheat germ. Unpowdered Lab Chow proved unsatisfactory, since it could be pouched or hidden in the nests.

One saccharin test was given 56 days after the introduction of the Lab Chow. A 0.1-g saccharin solution was presented in the same fashion as during the first experiment. Measures were taken for $4 \mathrm{~h}$ per day for 5 days.

\section{Results}

Food intake increased for both groups immediately after the introduction of Lab Chow. The orchidectomized group consumed a mean of $7.8 \mathrm{~g} / \mathrm{day}$, while the intact group consumed a mean of $7.0 \mathrm{~g} / \mathrm{day}$. This difference approached, but failed to reach, statistical significance. Both groups gained weight, with the intact group gaining a mean of $0.31 \mathrm{~g} / \mathrm{day}$ and the orchidectomized group gaining $0.69 \mathrm{~g} /$ day $(\mathrm{t}=7.88, \mathrm{df}=$ $12, \mathrm{p}<.05)$.

Within 3 weeks following the introduction of Lab Chow, the orchidectomized group had reached the same body weight as the intact group and gradually gained more weight than the intact group (groups, $F=5.17$, df $=1 / 10, \mathrm{p}<.05 ;$ Groups by Days, $\mathrm{F}=3.73, \mathrm{df}=59 / 590$, $\mathrm{p}<.05)$. The intact animals consumed reliably more saccharin than the orchidectomized group $(F=7.82, \mathrm{df}$ $=1 / 10, p<.05 ;$ Table 2 ), and both groups showed an increase in saccharin consumption over the 5-day testing period $(F=6.64, \mathrm{df}=4 / 40, \mathrm{p}<.05)$.

\section{DISCUSSION}

In previous research, it has been demonstrated that the effects of gonadectomy in rats on measures of taste preference and reactivity to electric shock were a function of body weight changes following gonadectomy (Marks \& Hobbs, 1972; Marks, Fargason, \& Hobbs, 1972). These data were offered in

Table 2

Mean Weight Gain and Saccharin Intake: Experiment II

\begin{tabular}{lcc}
\hline & $\begin{array}{c}\text { Body } \\
\text { Weight* }\end{array}$ & $\begin{array}{c}\text { Saccharin } \\
\text { Intake }\end{array}$ \\
\hline Intact & 53.0 & 2.8 \\
Orchidectomized & 69.2 & 1.9 \\
p & .05 & .05 \\
\hline
\end{tabular}

*Body weight gain was computed as the change, in grams, from preoperative body weight.

$\div$ Mean intake in milliliters over the 5-day testing period. opposition to the hypothesis that gonadal hormones have a direct effect on nonsexual behavior (Wade \& Zucker, 1969 , 1970; Zucker, 1969).

The data of the two experiments presented in this paper support the first viewpoint. Increased saccharin intake was found for orchidectomized hamsters when their body weight gain was reliably less than that of intact hamsters. A decrease in in take for the orchidectomized group was observed when they had gained more weight than the intact group. No differences in intake were observed when no weight differences existed.

This last point deserves some comment. Numerous authors, measuring either physiological or behavioral effects of castration, report that the effects of androgens dissipate slowly over time (Frye, 1967, Tepperman, 1968). This slow reduction in the effects of androgen would allow an alternative explanation of the results of the first saccharin test; namely, that the residual effects of the hormone rather than any weight differences may have been responsible for the lack of differences in saccharin intake. This interpretation is as tenable as the author's hypothesis on the basis of the first test. The absence of androgen during the second and third saccharin tests and the weight-intake relationships found during those tests are compatible with the author's hypothesis, but cannot be interpreted as supporting a direct hormone hypothesis.

In addition, it may be noted that during the second experiment, by which time both the intact and orchidectomized animals had gained reliably more weight than their testing weights during the first experiment, both groups showed a reliable decrease in saccharin intake. A matched-pairs t test found the difference in saccharin intake between the first and second experiments to be statistically significant $(\mathrm{t}=12.07, \mathrm{df}=$ $10, \mathrm{p}<.05$ ). It may be argued that the change in saccharin consumption was a function of age rather than weight. While the design of the experiment does not allow a resolution of this question, the lack of a consistent change from the first test in Experiment I to the second test in Experiment I argues against this interpretation.

Differences between the data presented in this study and those of Zucker et al (1972) may be a function of the testing procedures and/or the concentrations of saccharin used. Monroe, White; Lindsay, Dowling, \& Marks (1973) have shown that saccharin preference comparisons between intact and oophorectomized female rats are a function of the type of testing procedure (one-bottle vs two-bottle tests) and the concentration of saccharin used. Since Zucker et al used a two-bottle test, a 24-h intake measure and a different saccharin concentration, direct comparisons between the two studies may not be possible.

Regardless of the differences between this study and that of Zucker et al, it would appear that one cannot adequately evaluate the effects of gonadal hormones on behavior without also investigating the weight changes associated with these hormonal alterations. Since different foods have been shown to produce different effects on body weight, it would appear that additional consideration should be given to the animal's diet when making any variety of preference test.

\section{REFERENCES}

Frye, B. E. Hormonal control in vertebrates. New York: Macmillan, 1967.

Marks, H. E., Fargason, B. D., \& Hobbs, S. H. Reactivity to aversive stimuli as a function of alterations in body weight in normal and gonadectomized female rats. Physiology \& Behavior, 1972, 9, 539-544.

Marks, H. E., \& Hobbs, S. H. Changes in stimulus reactivity following gonadectomy in male and female rats of different ages. Physiology \& Behavior, 1972, 8, 1113-1119.

Marks, H. E., \& Miller, C. R. Development of hypothalamic obesity in the male golden hamster (Mesocricetus auratus) as a 
function of food preference. Psychonomic Science, 1972, 27, 263-265.

Monroe, R., White, F., Lindsay, B., Dowling, G., \& Marks, H. E. The effects of gonadectomy and weight gain on long term measures of saccharin consumption in female rats. Paper presented at the Southen Society for Philosophy and Psychology, 1973.

Robinson C J Proudfit-Robinson's normal and therapeutic nutrition. New York: Macmillan, 1967.

Tepperman, J. Metabolic and edocrine physiology. Chicago: Year Book Medical Publishers, 1968.

Wade, G. N., \& Zucker, I. Hormonal and developmental influences on rat saccharin preferences. Journal of Comparative Physiological Psychology, 1969, 69, 291-300.

Wade, G. N., \& Zucker, I. Hormonal modulation of responsiveness to an aversive taste stimulus in rats. Physiology \& Behavior, 1970, 5, 269-273.
Zucker, I. Hormonal determinants of sex differences in saccharin preference, food intake and body weight. Physiology \& Behavior, 1969, 4, 595-602.

Zucker, I., Wade, G. N., \& Ziegler. R. Sexual and hormonal influences on eating, taste preferences, and body weight of hamsters. Physiology \& Behavior, 1972, 8, 101-111.

\section{NOTE}

1. In all statistical tests, a predetermined alpha level of 0.05 was used. All results are therefore reported as statistically significant at or bey ond the 0.05 level or as statistically nonsignificant.

(Received for publication September 24, 1973.)

\section{Instruction effects in recognition memory*}

\author{
EUGENE B. ZECHMEISTER and CHRIS GUDE \\ Lovola University \\ 6525. Vorth Sherian Rd., Chicago, $\mathrm{Ml}$. 60626
}

Ninety-six Ss listened to a list of 200 common nouns after receiving instructions to study various portions of the list by repeating each word as it was presented (REP), producing associations to the study items (ASSOC), thinking of the "dictionary meaning" of each word (DM), and visualizing the spelling of each word (VS). One-half of the Ss were tested for forced-choice recognition of the nouns; the other half of the Ss were asked to identify for each study item the particular study strategy that had been used. Contrary to expectations of the frequency theory of recognition memory, recognition errors were significantly fewer under ASSOC or DM instructions than under REP instructions. However, retention of the kind of encoding activity indicates that Ss have available other information than frequency by which to make a recognition decision.

Light \& Selhorst (1971) and Hall \& Pierce (1972) have reported that recognition memory for common words was more accurate after Ss received instructions to produce associations to items at the time of study than after Ss were instructed to repeat study items or received neutral instructions. These results are in apparent conflict with predictions derived from the frequency theory of recognition memory (Underwood \&

*This article is based on research reported at the 45 th Annual Meeting of the Midwestern Psychological Association, Chicago. May 1973.
Freund, 1970). The rationale for this contradiction is as follows.

The frequency theory states that situational frequency is the dominant attribute mediating discrimination of "old" and "new" items in a recognition task. According to the theory, frequency accrues from both covert and overt representations of the item at the time of encoding, as well as from the addition of frequency units contributed by implicit associative responses (IARs) which are that word. When high-frequency words are presented for study and later test, IARs elicited during study may augment the frequency of other study items or may give frequency to new test items. Incrementing the situational frequency of old items via IARs should facilitate recognition performance, while incrementing the frequency of distractor items should inhibit performance. However, "since adding an additional frequency unit to an old word produces a relatively small increase in discriminability ... the negative effect (of IARs) should be greater than the positive effect [Underwood \& Freund, 1970, p. 345]." Since fewer IARs would be expected for low-frequency items, this reasoning provides a theoretical accounting in frequency terms for the empirical observation that recognition is poorer for high- than for low-frequency words (e.g., Gorman, 1961). When only high-frequency words are used, the same rationale would lead the frequency theory to predict poorer recognition as the likelihood of eliciting IARs during study is increased. At a minimum, if only a 